\title{
A trajetória das políticas de saúde mental e de álcool e outras drogas no século XX
}

\author{
The trajectory of mental health policies and alcohol \\ and other drugs in the twentieth century
}

Annabelle de Fátima Modesto Vargas ${ }^{1}$

Mauro Macedo Campos ${ }^{1}$

${ }^{1}$ Laboratório de Gestão e Políticas Públicas, Centro de Ciências do Homem, Universidade Estadual do Norte Fluminense Darcy Ribeiro. Av. Alberto Lamego 2000, Horto. 28013-600 Campos dos Goytacazes RJ Brasil.

annamodesto@hotmail.com

\begin{abstract}
The scope of this article is to analyze the temporal evolution of the rules that comprise the legal framework of public policies on mental health and on alcohol and other drugs between the years 1900 to 2000. The study seeks to analyze the trajectory of the rules to make it possible to understand a little more about the context and the way in which the issues related to these two themes were addressed prior to the Psychiatric Reform in Brazil, in 2001. For this purpose, documentary and bibliographical research was conducted, with the intention of enhancing the understanding of these two policies from a more normative angle. In the skein of legislation, 33 norms were cataloged which, after analysis, reveal the process of construction of the public policies related to the use of alcohol and other drugs, changing the repressive logic of justice and the "pathologization" of drug use and enabling the transition of the discussion from the field of security to that of public health, more specifically of mental health.
\end{abstract}

Key words Alcohol, Drugs, Mental health, Public policy
Resumo Este artigo tem por objetivo analisar a evolução temporal das regras que compõem o arcabouço legal das políticas públicas de saúde mental e de álcool e outras drogas entre os anos de 1900 até 2000. O estudo busca analisar a trajetória das regras, de modo que se possa compreender um pouco mais sobre o contexto e a forma no qual as questões relacionadas a estes dois temas foram tratados, até a Reforma Psiquiátrica no Brasil, em 2001. Para isso realizou-se uma pesquisa documental e bibliográfica, com o intuito de avançar no entendimento destas duas políticas sobre um ângulo mais normativo. Em um emaranhado de legislações, foram catalogadas 33 normas que, após análise, demonstram o processo de construção das políticas públicas relacionadas ao uso de álcool e outras drogas, alterando a lógica repressiva da justiça e da patologização do uso de drogas e possibilitando a transição da discussão do terreno da segurança para o da saúde pública, mais especificamente de saúde mental.

Palavras-chave Álcool, Drogas, Saúde mental, Políticas públicas 


\section{Introdução}

Este artigo é parte dos resultados de uma pesquisa de doutoramento. Tem por objetivo analisar a evolução temporal referente ao arcabouço legal sobre as políticas públicas de saúde mental e de álcool e outras drogas entre os anos de 1900 até 2000. A trajetória dessas regras, sobre tais políticas, não está claramente descrita e contextualizada pela literatura, a partir deste ângulo normativo.

Taniele Rui ${ }^{1}$ aponta a existência de lacunas na literatura e expõe caminhos a serem percorridos por novas pesquisas relacionadas a esta temática. Como aponta a autora, alguns acontecimentos "são transformações recentes que denotam como o consumo de drogas se tornou uma "questão de saúde pública" e, na prática, de 'saúde mental'”'. Busca-se aqui, compreender como se construíram as legislações que regulam políticas públicas de saúde mental, tendo como foco o uso de álcool e outras drogas e considerando o processo que culminou na Reforma Psiquiátrica (RP).

Após diversas experiências como o Movimento da Luta Antimanicomial, é promulgada, em 2001, a Lei 10.216 que redireciona o modelo de atenção em saúde mental no Brasil. Um dos seus propósitos é substituir progressivamente as internações em Hospitais Psiquiátricos por um cuidado no território, através dos Centros de Atenção Psicossocial (CAPS). Em meio a esse complexo processo, surge uma modalidade específica de CAPS, os CAPS ad, destinados a cuidar de pessoas que fazem uso de álcool e outras drogas².

Este artigo parte do entendimento da complexidade envolvida nesse processo. Como e de que maneira, pelo marco normativo, os usuários de álcool e outras drogas passam a ser atendidos pelos CAPS, mais especificamente, pelos CAPS ad? Mas, não se trata, no entanto, de um percurso meramente normativo. Ao contrário. É por meio do entendimento de uma "trajetória normativa" da política que se pretende identificar argumentos que nos ajudem a entender as tais "lacunas". Para tanto, pretende-se analisar esse percurso até o ano 2000, visto que em 2001 ocorre a III Conferência Nacional de Saúde Mental e a partir daí o Ministério da Saúde passa a prevenir, tratar e reabilitar usuários de álcool e outras drogas, como estabelecido na Conferência².

\section{Método}

Foi realizada uma pesquisa documental, qualitativa, que buscou catalogar e analisar as legisla- ções pertinentes à discussão da temática do álcool e outras drogas, entre 1900 e 2000. Esse recorte temporal leva em conta a promulgação da Lei 10.216, de 2001, considerada a "Lei da Reforma Psiquiátrica". Sobre este formato da pesquisa, autores como Sá-Silva et al. ${ }^{4}$ argumentam que a análise documental pode gerar uma riqueza de informações, possibilitando a apreensão de objetos cujo entendimento necessita da contextualização sociocultural e histórica. Minayo ${ }^{5}$ problematiza ainda, que a metodologia das pesquisas sociais é sempre polêmica, tendo questões não resolvidas, com debate permanente e não conclusivo.

Foram então levantadas a partir de consultas ao portal eletrônico do Planalto - armazenadas em: http://www4.planalto.gov.br/legislacao - leis, decretos e políticas publicadas no Diário Oficial da União. A pesquisa foi realizada utilizando separadamente os descritores: "droga", "mental", "mentais" e "manicômio"; para que fosse possível realizar a busca pelas legislações pertinentes. A procura se deu pelos termos exatos e não semelhantes, como possível pelo portal, e de modo separado. Isso porque, quando efetuado o rastreamento de forma conjunta com os descritores "droga" "mental", o resultado da busca foi de que não havia documentos dentro dos critérios selecionados.

Inicialmente se propunha a busca apenas pelos termos "droga" e "mental". No entanto, a partir do embasamento teórico, foi percebido que algumas legislações pertinentes à temática não apareciam no resultado das buscas. Assim, foram inseridos os novos descritores, "mentais" e "manicômio", entendendo que no período correspondente ao recorte da pesquisa, tais termos eram utilizados com maior frequência.

Como resultado destas novas buscas, temos: 1) com o descritor "droga", 113 documentos, sendo 25 selecionados para a pesquisa; 2) com o descritor "mental" foram encontrados 37 documentos, sendo 5 utilizados; 3 ) com o descritor "manicômio", 9 foram encontrados, sendo utilizados 2; e 4) com o termo "mentais", 28 foram encontrados, sendo apenas 1 utilizado.

A seleção das normas se deu em função de sua significância para a pesquisa, uma vez que muitas legislações que apareciam nesses resultados não tinham vinculação direta com a temática proposta. A exemplo dessa exclusão temos a Lei 7.713/1988, que altera a legislação do Imposto de Renda, embora apareça no resultado das buscas, não fornece elementos para o objetivo da pesquisa.

O quadro apresentado com as regras selecionadas não tem como proposta o esgotamento 


\section{Teoria, resultados e discussões}

Se o uso de álcool e outras drogas têm sido observado hoje como questão de saúde pública, mais especificamente, de saúde mental ${ }^{1}$, o cenário das regras, assim como a literatura especializada ${ }^{8,9}$ demonstram que houve momentos em que a questão foi tratada de modo meramente jurídico/policial. Neste caminho, a Secretaria Nacional de Políticas sobre Drogas (SENAD), do Ministério da Justiça, elabora um documento, fruto de uma "importante parceria estratégica" com a Universidade de São Paulo (USP), em 2010. Esta parceria se deu através das Faculdades de Medicina e Direito e resultou no projeto chamado "Integração de competências no desempenho da atividade judiciária com usuários e dependentes de drogas". Foi dividido em módulos: 1) A cultura jurídica sobre drogas; 2) Direitos Humanos; 3) Drogas; 4) Tratamento do uso prejudicial de drogas; 5) Prevenção do uso de drogas e redução de danos; e 6) Justiça restaurativa e as boas práticas nos juizados especiais criminais e varas da infância. De acordo com este documento, a Lei $\mathrm{n}^{\circ} 11.343 / 2006$ trouxe mudanças no que tange ao porte de drogas para consumo pessoal.

O texto aponta os efeitos e aspectos desta lei de 2006, no qual ressalta que o Brasil, concatenado à tendência mundial, afastou o sistema carcerário para dependentes e usuários de drogas, designando-lhes os sistemas de saúde e de assistência social. Nessa mesma linha, autores como Rodrigues et al. ${ }^{10}$ discutem que a Lei 11.343/2006 não prevê a legalização do uso de drogas, mas estabelece que o seu porte para consumo próprio perde a característica de "crime". Embora o usuário já não possa mais ser considerado "criminoso", outras sansões, que vão desde a aplicação de advertências verbais, à prestação de serviços públicos, continuam existindo.

Essa contextualização é importante para a compreensão da análise apresentada a seguir, que engloba as legislações anteriores ao período do ano 2000 e demonstram o desenrolar normati-

vo das políticas de álcool e drogas no Brasil. São apresentadas 33 legislações, que não necessariamente são discutidas de forma cronológica, no Quadro 1. O artigo se preocupa, então, em construir a trajetória global das regras, analisando-as a partir da literatura, não imperiosamente apresentando-as uma a uma.

A partir do Quadro 1 pode-se tecer algumas considerações. Das 33 legislações analisadas no período, tem-se que 69,7\% (23 legislações) referem-se às políticas de álcool e outras drogas. Chama atenção o fato de que a maior parte dessas regras (oito no total, 24,3\%) foram consumadas no período pós-redemocratização, a partir de 1986. Nos dois períodos de política mais austera, no Estado Novo (1937 - 1945) e no Regime Mili$\operatorname{tar}(1964$ - 1985), ambos foram responsáveis pela edição de seis legislações $(18,2 \%)$. No tocante às regras sobre saúde mental, $24,2 \%$ trataram exclusivamente deste tema (oito legislações), sendo que a maior parte destas regras, quatro no total (50\%), foram editadas na década de 1920. Das outras quatro duas foram no governo Vargas uma dessas no Estado Novo -, uma outra na experiência democrática de 1946 e a última já na redemocratização, em 1989. Apenas duas legislações abordam as duas temáticas, álcool e outras drogas e saúde mental. $\mathrm{E}$ as duas foram editadas em 1921.

Ao aderir à Convenção de Haia, o Brasil formula os decretos no 4.294 em 1921 e no 15.683 de 1922. Além do decreto no 14.969 , de 1921, que cria o "sanatório para toxicômanos"11. Tais regras confirmavam as propostas estabelecidas em Haia, onde foi definido o primeiro tratado internacional que propunha controle na venda de morfina, ópio, cocaína e heroína. Seguindo a tendência da Convenção, os citados decretos, definiram pena de prisão aos que vendessem ópio e seus derivados, além de punir com internação compulsória a embriaguez que causasse atos nocivos a outrem, si próprio ou à ordem pública ${ }^{8}$.

No mesmo ano, em 1921, através do decreto $\mathrm{n}^{\circ} 14.831$, ocorreu a criação do primeiro manicômio judiciário do Brasil e América Latina, chamado Manicômio Judiciário do Rio de Janeiro. Segundo Santos e Faria ${ }^{12}$, esta modalidade de manicômio, surge ancorada em saberes que permeiam o crime e a loucura, tendo como abrangência uma discussão teórica que embasava a relação entre as escolas jurídicas e a psiquiatria. Tempos depois, em 1986, o manicômio passou a ser chamado "Hospital de Custódia e Tratamento Psiquiátrico Heitor Carrilho" e ficou conhecido por ter sido cenário do filme $\mathrm{Meu}$ nome não 
Quadro 1. Trajetória das legislações em saúde mental, álcool e outras drogas no Brasil de 1900 a 2000.

\begin{tabular}{|c|c|c|c|c|}
\hline Ano & Legislação & Síntese do Conteúdo & $\begin{array}{c}\text { Álcool e } \\
\text { Outras Drogas }\end{array}$ & $\begin{array}{l}\text { Saúde } \\
\text { Mental }\end{array}$ \\
\hline 1903 & Lei n. 1.132 & Reorganiza a assistência a alienados & - & $\mathrm{X}$ \\
\hline 1914 & $\begin{array}{l}\text { Decreto } n . \\
2.861\end{array}$ & $\begin{array}{l}\text { Aprova as medidas tendentes a impedir o abuso crescente do ópio, da } \\
\text { morfina e seus derivados, bem como da cocaína, constantes das resoluções } \\
\text { aprovadas pela Conferência Internacional de Ópio, de } 1911 \text { em Haya. }\end{array}$ & $\mathrm{X}$ & - \\
\hline 1921 & $\begin{array}{l}\text { Decreto } n . \\
4.294\end{array}$ & $\begin{array}{l}\text { Estabelece penalidades para os contraventores na venda de cocaína, ópio, } \\
\text { morfina e seus derivados; cria um estabelecimento especial para internação } \\
\text { dos intoxicados pelo álcool ou substâncias venenosas; estabelece as formas de } \\
\text { processo e julgamento e manda abrir os créditos necessários. }\end{array}$ & $\mathrm{X}$ & $\mathrm{X}$ \\
\hline 1921 & $\begin{array}{l}\text { Decreto } n . \\
14.969\end{array}$ & $\begin{array}{l}\text { Aprova o regulamento para a entrada no país das substâncias tóxicas, } \\
\text { penalidades impostas aos contraventores e sanatório para toxicômanos. }\end{array}$ & $\mathrm{X}$ & $\mathrm{X}$ \\
\hline 1921 & $\begin{array}{l}\text { Decreto } n . \\
14.831\end{array}$ & Aprova o Regulamento do Manicômio Judiciário. & - & $\mathrm{X}$ \\
\hline 1923 & $\begin{array}{l}\text { Decreto } \mathrm{n} . \\
4.778\end{array}$ & $\begin{array}{l}\text { Considera de utilidade pública a Liga Brasileira de Higiene Mental, com sede } \\
\text { nesta Capital }\end{array}$ & - & $\mathrm{X}$ \\
\hline 1927 & $\begin{array}{l}\text { Decreto n. } \\
5.148-\mathrm{a}\end{array}$ & Reorganiza a Assistência a Psicopatas no Distrito Federal. & - & $\mathrm{X}$ \\
\hline 1932 & $\begin{array}{l}\text { Decreto } n . \\
20.930\end{array}$ & $\begin{array}{l}\text { Define a fiscalização do emprego e do comércio das substâncias tóxicas } \\
\text { entorpecentes, regula a sua entrada no país de acordo com a solicitação do } \\
\text { Comitê Central Permanente do Ópio da Liga das Nações, e estabelece penas. }\end{array}$ & $\mathrm{X}$ & - \\
\hline 1934 & $\begin{array}{l}\text { Decreto } n . \\
24.559\end{array}$ & $\begin{array}{l}\text { Dispõe sobre a profilaxia mental, a assistência e proteção a pessoa e aos bens } \\
\text { dos psicopatas, a fiscalização dos serviços psiquiátricos }\end{array}$ & - & $\mathrm{X}$ \\
\hline 1936 & $\begin{array}{l}\text { Decreto n. } \\
780\end{array}$ & Cria a Comissão Permanente de Fiscalização de Entorpecentes. & $\mathrm{X}$ & - \\
\hline 1938 & $\begin{array}{l}\text { Decreto } \mathrm{n} . \\
2.953\end{array}$ & $\begin{array}{l}\text { Modifica o art. } 2^{\circ} \text { do decreto n. } 780 \text {, de } 28 \text { de abril de 1936, que criou a } \\
\text { Comissão Permanente de Fiscalização de Entorpecentes. }\end{array}$ & $\mathrm{X}$ & - \\
\hline 1938 & $\begin{array}{l}\text { Decreto- } \\
\text { Lei n. } 891\end{array}$ & Aprova a Lei de Fiscalização de Entorpecentes. & $\mathrm{X}$ & - \\
\hline 1940 & $\begin{array}{l}\text { Decreto- } \\
\text { Lei n. } 2.848\end{array}$ & Promulga o Código Penal. & $\mathrm{X}$ & - \\
\hline 1941 & $\begin{array}{l}\text { Decreto- } \\
\text { Lei n. } 3.688 \\
\end{array}$ & Lei das contravenções penais. & $\mathrm{X}$ & - \\
\hline 1941 & $\begin{array}{l}\text { Decreto- } \\
\text { Lei n. } 3.114\end{array}$ & Dispõe sobre fiscalização de entorpecentes. & $\mathrm{X}$ & - \\
\hline 1941 & $\begin{array}{l}\text { Decreto-lei } \\
\text { n. } 3.497\end{array}$ & $\begin{array}{l}\text { Cria, no Serviço Nacional de Doenças Mentais do Departamento Nacional de } \\
\text { Saúde do Ministério da Educação e Saúde, o Hospital de Neuro-Psiquiatria } \\
\text { Infantil }\end{array}$ & - & $\mathrm{X}$ \\
\hline 1942 & $\begin{array}{l}\text { Decreto- } \\
\text { Lei n. } 4.720 \\
\end{array}$ & $\begin{array}{l}\text { Fixa normas gerais para o cultivo de plantas entorpecentes e para a extração, } \\
\text { transformação e purificação dos seus princípios ativo-terapêuticos. }\end{array}$ & $\mathrm{X}$ & - \\
\hline 1946 & $\begin{array}{l}\text { Decreto-lei } \\
\text { n. } 8.550\end{array}$ & $\begin{array}{l}\text { Autoriza o Ministério da Educação e Saúde a celebrar acordos, visando a } \\
\text { intensificação da assistência psiquiátrica }\end{array}$ & - & $\mathrm{X}$ \\
\hline 1964 & Lei n. 4.483 & Reorganiza o Departamento Federal de Segurança Pública & $\mathrm{X}$ & - \\
\hline 1967 & $\begin{array}{l}\text { Decreto- } \\
\text { Lei n. } 159\end{array}$ & $\begin{array}{l}\text { Dispõe sobre as substâncias capazes de determinar dependência física ou } \\
\text { psíquica. }\end{array}$ & $\mathrm{X}$ & - \\
\hline 1968 & $\begin{array}{l}\text { Decreto- } \\
\text { Lei n. } 385\end{array}$ & Dá nova redação ao artigo n. 281 do Código Penal. & $\mathrm{X}$ & - \\
\hline 1971 & Lei n. 5.726 & $\begin{array}{l}\text { Dispõe sobre medidas preventivas e repressivas ao tráfico e uso de substâncias } \\
\text { entorpecentes ou que determinem dependência física ou psíquica. }\end{array}$ & $\mathrm{X}$ & - \\
\hline 1976 & Lei n. 6.368 & $\begin{array}{l}\text { Dispõe sobre medidas de prevenção e repressão ao tráfico ilícito e uso } \\
\text { indevido de substâncias entorpecentes ou que determinem dependência física } \\
\text { ou psíquica. }\end{array}$ & $\mathrm{X}$ & - \\
\hline 1980 & $\begin{array}{l}\text { Decreto } n . \\
85.110\end{array}$ & $\begin{array}{l}\text { Institui o Sistema Nacional de Prevenção, Fiscalização e Repressão de } \\
\text { Entorpecentes. }\end{array}$ & $\mathrm{X}$ & - \\
\hline
\end{tabular}


Quadro 1. Trajetória das legislações em saúde mental, álcool e outras drogas no Brasil de 1900 a 2000.

\begin{tabular}{|c|c|c|c|c|}
\hline Ano & Legislação & Síntese do Conteúdo & \begin{tabular}{|c|} 
Álcool e \\
Outras Drogas
\end{tabular} & $\begin{array}{l}\text { Saúde } \\
\text { Mental }\end{array}$ \\
\hline 1986 & Lei n. 7.560 & $\begin{array}{l}\text { Cria o Fundo de Prevenção, Recuperação e de Combate às Drogas de Abuso, } \\
\text { dispõe sobre os bens apreendidos e adquiridos com produtos de tráfico ilícito } \\
\text { de drogas ou atividades correlatas. }\end{array}$ & $\mathrm{X}$ & - \\
\hline 1989 & $\begin{array}{l}\text { Projeto de } \\
\text { lei n. } 3.657\end{array}$ & Dispõe sobre a extinção progressiva dos manicômios. & - & $\mathrm{X}$ \\
\hline 1990 & Lei n. 8.072 & Dispõe sobre os crimes hediondos & $\mathrm{X}$ & - \\
\hline 1993 & Lei n. 8.764 & $\begin{array}{l}\text { Cria a Secretaria Nacional de Entorpecentes e altera a redação dos art. } 2 \text { e } 5 \\
\text { da Lei n. 7.560/1986. }\end{array}$ & $\mathrm{X}$ & - \\
\hline 1995 & Lei n. 9.099 & Dispõe sobre os juizados especiais cíveis e criminais. & $\mathrm{X}$ & - \\
\hline 1996 & Lei n. 9.294 & $\begin{array}{l}\text { Dispõe sobre as restrições ao uso e à propaganda de produtos fumígeros, } \\
\text { bebidas alcoólicas, medicamentos, terapias e defensivos agrícolas }\end{array}$ & $\mathrm{X}$ & - \\
\hline 1998 & $\begin{array}{l}\text { Decreto } n . \\
2632\end{array}$ & Dispõe sobre o Sistema Nacional Antidrogas. & $\mathrm{X}$ & - \\
\hline 1998 & $\begin{array}{l}\text { Portaria n. } \\
344\end{array}$ & $\begin{array}{l}\text { Aprova o Regulamento Técnico sobre substâncias e medicamentos sujeitos a } \\
\text { controle especial. (ANVISA). }\end{array}$ & $\mathrm{X}$ & - \\
\hline 1999 & Lei n. 9.804 & $\begin{array}{l}\text { Altera a redação do art. } 34 \text { da Lei n. 6.368-1976, que dispõe sobre medidas } \\
\text { de prevenção e repressão ao tráfico ilícito e uso indevido de substâncias } \\
\text { entorpecentes ou que determinem dependência física ou psíquica. }\end{array}$ & $\mathrm{X}$ & - \\
\hline
\end{tabular}

Fonte: Elaborado pelos autores a partir das legislações.

é Johnny, de 2008, mostrando que dependentes químicos masculinos ficavam abrigados no hospital.

Como forma de se esquivar, como discutido por Reis ${ }^{13}$, de uma suposta degradação física e mental da população, é criada em 1923 a Liga Brasileira de Higiene Mental, que para Amarante $^{14}$ significa a cristalização de um movimento com características eugênicas que tinha propostas que cerceavam a liberdade e cidadania ${ }^{13}$. Já no ano de 1927, através do decreto no 5.148 -A, a assim denominada "assistência a psicopatas" é reorganizada e estabelece que, “(...) a pessoa que, em consequência de doença mental, congênita ou adquirida, atentar contra a própria vida ou a de outrem, perturbar a ordem ou ofender a moral publica, será recolhida a estabelecimento apropriado para tratamento".

Esses estabelecimentos apropriados seriam os manicômios judiciários anteriormente criados, ficando disposto neste último decreto que seria proibido manter os "psicopatas em cadeias públicas ou entre criminosos.

A partir de 1936 percebe-se um aumento na preocupação com a questão do uso de substâncias entorpecentes, sendo criada uma Comissão Permanente de Fiscalização. Em 1938 publicouse o decreto-lei ${ }^{\circ} 891$, que condenava o uso do ópio e da cocaína, incluindo também a maconha e a heroína. Assim, o uso de drogas aparece classificado como "toxicomania", doença de notificação compulsória, não podendo ser tratada em domicílio. A internação em manicômios diante desses casos e mesmo nos de intoxicação por bebidas alcoólicas era entendida como obrigatória quando estabelecida pelo juiz, ou facultativa ${ }^{15}$.

Interessante notar como a questão do uso de drogas aparece, já nesse momento, como uma questão de saúde, ou, mais precisamente, de doença. Silva ${ }^{16}$ faz uma investigação histórica do uso de droga enquanto objeto de intervenção da Psiquiatria e da Justiça, partindo do século XX até os dias atuais. A autora reflete sobre a articulação e cooperação entre as duas instituições, encontrando convergências e divergências dos processos de medicalização e criminalização do uso da droga, enfocando a organização atual da problemática.

A discussão que se apresenta já nos indica caminhos a serem seguidos no que tange à patologização do uso de drogas e no sentido das normativas que foram surgindo ao longo do tempo. Vê-se que as questões jurídicas e de medicina acabam por manter uma relação dialética, embora aparentemente polêmicas. Como analisado por Castel ${ }^{17}$, essas instituições socialmente reconhecidas, a justiça e a medicina, se apropriam de determinado objeto - o uso de drogas - através 
de um poder legitimado e exercem seus domínios, direcionando a temática para uma questão de Estado e que exige intervenções normativas.

Vargas $^{18}$ indica a polissemia do termo "drogas", que mantém fronteiras imprecisas com outras categorias como "alimentos", "venenos" e "remédios". Segundo o autor, essa questão não está vinculada a uma simples experiência de uso enquanto tal, mas ao processo ativo de apropriação dessa experiência enquanto fenômeno digno de intervenção médica e jurídica indistintamente, o que torna a criminalização e medicalização as principais vias de criação do evento da droga nas sociedades modernas.

Segundo Machado e Miranda ${ }^{8}$, as intervenções iniciais do governo brasileiro se deram através da criação de um aparato jurídico-institucional, no início do século XX, destinado a garantir o controle do comércio e do uso de drogas, preservando a segurança e saúde pública no país. Os autores afirmam que nessa época, o consumo de drogas era ainda incipiente, não constituindo uma ameaça à saúde. No entanto, o uso de bebidas alcoólicas era constante, mas não era motivo de preocupação, uma vez que seu consumo era tolerado pela sociedade e também pelo governo.

Nesse período surgiram, como apontado por Musumeci ${ }^{19}$, sociedades privadas como a Liga Antialcoólica de São Paulo, Liga Brasileira de Higiene Mental, Liga Paulista de Profilaxia Moral e Sanitária e União Brasileira Pró-Temperança, que tinham por objetivo promover assistência aos alcoolistas e dependentes químicos. Essas instituições eram marcadas por princípios higienistas e moralistas. A questão legal referente às drogas permanecia frágil e sem uma organização que pudesse ser considerada objetiva até o início do século $\mathrm{XX}^{8,11}$.

Em 1932 é instituído o decreto no 20.930, que integrou a Consolidação das Leis Penais, fixando pena de reclusão e multa para ações de comércio e indução ao uso, além de pena de prisão para posse ilícita de drogas sem receita médica ou superando as quantidades terapêuticas indicadas ${ }^{11}$. Já nesse período o poder médico legitima a posse de algumas drogas, conferindo a elas um estatuto de "licitudes" e "ilicitudes". Assim, ter posse da droga com uma receita médica legitima seu uso, que passa a ser visto como controlado. Indo além, as quantidades também são controladas e quando estão fora de uma dosagem considerada "terapêutica" pelos profissionais de saúde, já há um indicativo para punições.

Necessário então construir melhor essa ideia em relação à categorização de certas drogas em lícitas e ilícitas. O século XX, segundo Carneiro ${ }^{20}$, ficou marcado pelo que foi considerado "guerra às drogas", não apenas em função das normativas da ONU, mas também face aos interesses políticos e econômicos dos Estados Unidos. Com a expansão da indústria farmacêutica e das normas internacionais, as drogas foram classificadas em lícitas e ilícitas, categorizando o que passou a ser considerado medicamento, alimento e condimento. Vargas $^{18}$ expõe que alguns alimentos como chá, café, açúcar e chocolate foram, entre os séculos XVII e XVIII, rechaçados pela igreja católica por sua função estimulante, ou aceitos apenas para consumo por alguns níveis sociais. Isso, segundo Silva e Delduque ${ }^{21}$, chama a atenção para o fato de que a criminalização das drogas é um processo social recente.

Silva ${ }^{16}$ argumenta que ao final dos anos de 1930 havia um panorama caracterizado pelo tom alarmante e epidêmico em relação à construção do discurso sobre a temática da droga no âmbito médico e jurídico. A retenção dos toxicômanos era amparada tanto pela justiça, legalmente, quanto cientificamente, pela psiquiatria, defendendo seu discurso terapêutico. O toxicômano, era visto como ameaça, sendo incapaz de viver de acordo com os preceitos de civilidade, representando um risco para si e para o seu entorno.

Em 1938 é criada a Comissão Nacional de Fiscalização de Entorpecentes (CONFEN), vinculada ao Ministério da Saúde. O decreto no 891 de 1938, resultante da Convenção de Genebra de 1936, determina pena de prisão para o caso de consumo de drogas e apresenta o rol de substâncias assim consideradas, estabelecendo um conjunto de infrações penais, dentre elas a internação e interdição civil dos considerados toxicômanos.

No ano de 1940, através do decreto-lei ${ }^{\circ}$ 2.848 é instituído o Código Penal, que regulamenta a pena de reclusão e multa a quem "importar ou exportar, vender ou expor à venda, fornecer, ainda que a título gratuito, transportar, trazer consigo, ter em depósito, guardar, ministrar ou, de qualquer maneira, entregar a consumo substância entorpecente, sem autorização ou em desacordo com determinação legal". Posterior à instituição do Código Penal de 1940, alguns mecanismos legais vinculados à temática foram editados, como o decreto-lei no 3.114 de 1941, que criou uma Comissão Nacional de Fiscalização de entorpecentes e o decreto-lei no 4.720 de 1942, que fixava as normas para o cultivo de plantas entorpecentes e para a extração, transformação e purificação de seus princípios ativos terapêuticos ${ }^{11}$. 
Uma postura proibicionista, para Garcia et al. ${ }^{22}$ e Wandekoken e Dalbello-Araújo', é apresentada pelo Código Penal de 1940, sendo que muitas das normas expressas pelo documento figuram aspectos inerentes à gestão do Presidente Getúlio Vargas (1930-1945). Dessa forma, para os autores, a criminalização ficava evidente, independentemente da quantia da droga e da diferenciação entre uso próprio ou tráfico.

De maneira diversa, Silva ${ }^{16}$, argumenta que as décadas de 1940 e 1950, são vistas, no âmbito da política criminal, como um momento liberalizante. O fato de o Código Penal de 1940 criminalizar o ato de portar o entorpecente acarretava uma ambiguidade por não esclarecer se o caráter criminalizante incluía o "trazer consigo", para uso próprio ou apenas para a comercialização. Para Batista $^{23}$, o que pode ser compreendido é que há uma propensão para a descriminalização, já que a questão da droga era principalmente tratada de modo médico, vigorando até a década de 1960 um "modelo sanitário" de intervenção.

Lima $^{11}$ ressalta que nesse período, anterior à década de 1960, os toxicômanos deveriam ser tratados como "doentes" e não como "delinquentes" e, por isso, seriam, compulsoriamente, internados em estabelecimentos hospitalares. Nessa época, de acordo com Silva ${ }^{16}$, a droga ainda não era vista como um "problema", já que sua importância político-econômica era pequena, ficando seu uso restrito a alguns grupos, não atingindo a população de forma geral.

Já no final da década de 1950 e a partir de 1960 essa perspectiva começa a mudar mundialmente. Em 1957 é criada, como medida de repressão, a primeira Delegacia de Polícia especializada em tóxicos no Brasil, mais especificamente em São Paulo ${ }^{11}$. No entanto, o consumo de droga tornou-se mais popular a partir da década de 1960, estando muito associado aos movimentos da contracultura ${ }^{16}$.

A ideia do proibicionismo e da "guerra às drogas" tem sua origem atribuída aos Estados Unidos, através das políticas adotadas a partir dos anos de 1960 e 1970. Acontece nesse período o aumento da demanda por maconha, haxixe e cocaína, impulsionando a composição dos cartéis de produção na Colômbia, Bolívia e Peru, dando início ao que se considera o ciclo contemporâneo da história da droga ${ }^{24}$. Rodrigues ${ }^{25}$ reforça que a transição da esfera individual a um problema de Estado no que tange à questão das drogas é resultado de um conjunto de fatores sociais, políticos, econômicos, morais e religiosos que surgem a partir da influência internacional com a emergência dos EUA enquanto potência.

Nos anos de 1961, 1971 e 1988, como já dito, aconteceram as Convenções-Irmãs, que representaram fortemente a ideia da "guerra às drogas" influenciando diversos países, dentre eles o Brasil ${ }^{9}$. Na esteira deste processo, a Lei $n^{\circ} 4.483$ de 1964 reorganiza o Departamento Federal de Segurança Pública, criando um Serviço de Repressão a Tóxicos e Entorpecentes. Interessante notar, como aponta Carvalho ${ }^{26}$, que há uma transição da política criminal uma vez que o termo "fiscalização" é substituído por "repressão", indicando uma alteração de um modelo sanitário de política sobre drogas para um modelo bélico, o que demonstra uma nova ideologia em termos da segurança nacional.

Lima $^{11}$ destaca também que através do Decreto-Lei no 159 de 1967, o Brasil passa a assemelhar as substâncias que pudessem ocasionar dependência física ou psíquica, como alucinógenos e anfetaminas, às drogas com finalidade penal, devendo o Serviço Nacional de Saúde (SNFMF) relacionar tais substâncias. Nos anos de 1968 e 1969 acontecem também modificações consideráveis no que tange a posse para consumo ou venda.

Através dessa alteração o usuário torna-se sujeito a uma punição, uma vez que o consumo passa a ser entendido como algo que mantém vivo o tráfico. Mais adiante, em $1971 \mathrm{com}^{2}$ Lei n ${ }^{\circ}$ 5.726, novas medidas repressivas e, na concepção da época, preventivas são estabelecidas, passando traficante e usuário a ter a mesma tipificação penal e igual tratamento. Essa Lei estabeleceu a maior pena a usuários já vista na legislação brasileira: prisão de 1 a 6 anos e multa, atingindo indistintamente traficante e comprador ${ }^{11}$. Silva ${ }^{16}$ explica que a situação brasileira na época contradizia a tendência internacional do período: se no mundo operava, segundo Del Olmo ${ }^{27} \mathrm{o}$ "discurso médico-sanitário-jurídico", o que se via por aqui era um aparente retrocesso no caminho da descriminalização e priorização do tratamento médico ${ }^{16}$.

Machado e Miranda ${ }^{8}$ discutem que a medicina influenciou fortemente a legislação brasileira a partir da década de 1970 legitimando, através do discurso tecnocientífico, o controle do uso de drogas. Sendo o usuário visto como criminoso e/ou doente, foi proposto para o seu tratamento os hospitais psiquiátricos, a princípio e, seguidamente, centros especializados de tratamento, filantrópicos ou públicos. Ainda segundo os autores, esses locais tinham a missão de "salvar, recuperar, tratar e punir", o que denota uma im- 
pressão ainda constatada nos dias de hoje, evidenciando as diversas motivações que perpassam as práticas de saúde na área.

O ano de 1976 constitui um marco pela intervenção da ONU na procura pela instauração de medidas de controle do tráfico e uso de substâncias psicotrópicas em todo o mundo, o que, para Lima $^{11}$, ocasionou um aumento da preocupação pelos operadores do direito no Brasil. Foi então promulgada a Lei $n^{\circ} 6.368$, que segundo Machado e Miranda ${ }^{8}$ corroborou para a abordagem da dependência e uso de drogas na esfera médico -psiquiátrica.

Cláudia Silva ${ }^{16}$ explica que uma modificação importante no campo da Psiquiatria também ocorreu na década de 1970: a elaboração da terceira edição do Manual Diagnóstico e Estatístico de Transtornos Mentais (DSM), discutido ao longo da década de 1970, mas publicado em 1980. Este manual é um documento que marca uma mudança nos sentidos da Psiquiatria mundial e no tocante à questão das drogas um elemento importante precisa ser considerado: seu uso deixa de estar presente entre o conjunto de transtornos de personalidade e aparece com a denominação "transtorno de uso de substância" ${ }^{16}$. Isso significa que há uma modificação quando comparado às duas edições anteriores. O transtorno de uso de substâncias, conforme o manual, torna-se independente dos transtornos de personalidade e há o incremento de uma nova categoria, "abuso", passando-se a considerar patológicas medidas cada vez menores de consumo. Tudo isso possibilitou que um número maior de indivíduos, fossem inseridos nessa categoria, havendo o que a autora denomina "afrouxamento" dos critérios diagnósticos, permitindo um significativo aumento da atuação da Psiquiatria sobre a questão das drogas.

$\mathrm{Na}$ década de 1980 importantes acontecimentos ocorreram tanto no sentido da atuação em saúde mental, quanto na elaboração de políticas voltadas para a questão do álcool e outras drogas. Um desses acontecimentos é a ampliação do Movimento da Luta Antimanicomial. Lüchmann e Rodrigues ${ }^{28}$ discutem que as primeiras manifestações no setor de saúde surgem em 1976 com a constituição do Centro Brasileiro de Estudos de Saúde (CEBES), no contexto de abertura do regime militar, sendo um espaço de discussão e possibilitando a produção crítica na área. É nesse espaço que surge o Movimento dos Trabalhadores em Saúde Mental, denunciando o sistema nacional de assistência psiquiátrica, indicando fraudes, torturas e tratamento desumano aos pa- cientes psiquiátricos. Os autores apontam que no período de seis anos, que vão de 1987 até 1993, diversas articulações foram realizadas e em 1993 o Movimento Nacional da Luta Antimanicomial foi consolidado. É neste cenário que se é apresentado, em setembro de 1989, o Projeto de Lei no 3.657, de autoria do deputado federal Paulo Delgado, que propunha a extinção progressiva dos manicômios. Tal Projeto de Lei ficou por 12 anos em tramitação, sofrendo diversas alterações, até por fim ser aprovada, em abril de 2001 a Lei ${ }^{\circ}$ $10.216^{29}$. Importante demarcar que a proposição de análise neste artigo vai apenas até o ano 2000, sendo que a Lei $\mathrm{n}^{\circ} 10.216$ de 2001 , que regulamente a Reforma Psiquiátrica no Brasil é apontada por ser resultante de um processo iniciado em 1989. De outro lado, através do decreto no 85.110 de 1980, é instituído o Sistema Nacional de Prevenção, Fiscalização e Repressão de Entorpecentes. Assim, foi definido como órgão central do Sistema Nacional o Conselho Federal de Entorpecentes (COFEN).

Segundo Machado e Miranda ${ }^{8}$ o COFEN sobressaiu-se como órgão normativo dos variados temas e das ações governamentais programáticas dedicadas ao controle das drogas. Era formado por diversos ministérios, como o da Justiça, da Saúde, da Educação e Cultura, da Previdência e Assistência Social, da Fazenda e das Relações Exteriores. Inicialmente somente as questões relativas às drogas ilícitas eram abordadas. Mas ainda na década de 1980 passou a englobar também discussões relacionadas às drogas lícitas.

Ao longo da década de 1990, já no governo de Fernando Henrique Cardoso, o Sistema Nacional de Prevenção, Fiscalização e Repressão de Entorpecentes é substituído pelo Sistema Nacional Antidrogas (SISNAD) e pela Secretaria Nacional Antidrogas (SENAD). A SENAD era um órgão ligado ao então Gabinete Militar da Presidência da República e sua elaboração demonstrou uma estratégia política do Estado brasileiro em transparecer à comunidade internacional iniciativas que corroboravam com a ideia de que o combate às drogas era uma prioridade do governo. Além disso, tal secretaria era responsável pela coordenação e articulação da Política Nacional Antidrogas (PNAD), de $2002^{22}$.

O COFEN foi extinto em 1998 e substituído pelo Conselho Nacional Antidrogas (CONAD). O SISNAD norteia-se pelo princípio da responsabilização compartilhada pelo Estado e a Sociedade, entendendo que governo, cidadãos e a iniciativa privada precisam cooperar mutuamente. Um dos objetivos apresentados pelo sistema 
é a criação de uma Política Nacional Antidrogas, com ideais alinhados ao proibicionismo. Interessante notar que o foco mantido pelo governo FHC alinhava-se a uma perspectiva "antidroga", o que mantém o foco na ideia de combatê-la ${ }^{22}$.

Neste período há um aperfeiçoamento das estratégias elaboradas para combater o uso da dro$\mathrm{ga}^{16}$. Tanto que, através da Lei $\mathrm{n}^{\circ} 7.560$ de 1986 foi criado o Fundo de Prevenção, Recuperação e de Combate às Drogas de Abuso (FUNCAB), com a finalidade de financiar as medidas sugeridas no período, sendo as ações sanitárias voltadas primordialmente para os sujeitos considerados dependentes, reforçando os estereótipos de criminoso e doente, além de serem vinculadas ao Ministério da Justiça e não à área da saúde. No âmbito internacional, em 1998, a ONU convoca uma Assembleia Geral com a finalidade de debater uma política mundial sobre drogas e estabelece como objetivo a ser atingido até 2008: "Um mundo livre de drogas: nós podemos fazê-lo" .

Pode-se perceber, por fim, que durante o século XX a discussão sobre o uso de álcool e drogas esteve fortemente atrelada às práticas psiquiátricas e ao estatuto da "doença mental" seja como condicionante ou como resultante do uso de substâncias psicoativas. As terminologias utilizadas - toxicômanos, dependente de drogas, usuário de drogas - denotam uma trajetória que se conforma à evolução das políticas voltadas para esse campo.

\section{Considerações finais}

O debate aqui proposto buscou investigar, mediante as pistas deixadas por Rui ${ }^{1}$, a trajetória das legislações direcionadas à questão do uso de álcool e outras drogas no Brasil, desembocando no entendimento de que a partir dos anos 2000 ocorre uma transição no sentido de pensar a questão pelo viés da "saúde pública", mais especificamente da "saúde mental". Nota-se que as discussões no ambiente científico atual se or- ganizam frente a duas lógicas: a da repressão e proibição, à contenda da segurança pública e o da redução e danos e cuidado no território, a partir da saúde mental. Na prática parece ainda não ter acontecido uma completa fusão entre os dois tipos de políticas públicas nos termos da temática do uso de drogas até o final dos anos 2000.

Importante salientar a forte influência da Psiquiatria na sustentação das ideias repressivas da justiça e da patologização do uso de drogas, possibilitando a transição da discussão do terreno da segurança para o da saúde pública. A elaboração de novos critérios diagnósticos proporcionou um aumento no número de casos passíveis de intervenção, conferindo o estatuto médico ao que antes era tratado de modo policial. Tais pistas encontradas pelo sobrevôo às normas ao longo deste último século, nos permite analisar como as políticas desenvolvidas no século XXI seguem esses caminhos históricos, que se iniciaram nos primeiros anos do século XX. E, o que se buscou neste artigo, com o delineamento e construção da trajetória das normas, foi exatamente demonstrar como essa transformação vem ocorrendo e como ela se desenha na construção das políticas de saúde que são implantadas no século XXI.

\section{Colaboradores}

AFM Vargas participou da concepção, redação, análise e interpretação dos dados. MM Campos participou da análise e interpretação dos dados e redação final. 


\section{Referências}

1. Rui T. Nas tramas do crack: etnografia da abjeção. São Paulo: Terceiro Nome; 2014.

2. Santos CE, Yasui S. Muito Além do Caps AD: o cuidado no território e na vida. In: Souza AC, Souza LF, Souza EO, Abrahão EL, organizadoras. Entre pedras e fissuras: a construção da atenção psicossocial de usuários de drogas no Brasil. São Paulo: Hucitec; 2016. p. 70-87.

3. Pitta AMF. Um balanço da reforma psiquiátrica brasileira: instituições, atores e políticas. Cien saude colet 2011; 10(12):4579-4589.

4. Sá-Silva JR, Almeida CD, Guindani JF. Pesquisa documental: pistas teóricas e metodológicas. Rev Bras Hist \& Cien Sociais 2009; 1(1):1-15.

5. Minayo MCS. O desafio do conhecimento: pesquisa qualitativa em saúde. $5^{a}$ ed. São Paulo: Hucitec; 1998.

6. Brasil. Ministério da Saúde (MS). Legislação em Saúde Mental - 2004 a 2010. Brasília: MS; 2010. Ed. XII Colegiado de Coordenadores de Saúde Mental.

7. Brasil. Ministério da Justiça (MJ). Secretaria Nacional de Políticas sobre Drogas. Integração de competências no desempenho da atividade judiciária com usuários e dependentes de drogas. $2^{\text {a }}$ ed. Brasília: MJ; 2015.

8. Machado AR, Miranda PSC. Fragmentos da história da atenção à saúde para usuários de álcool e outras drogas no Brasil: da Justiça à Saúde Pública. Hist cienc saúde -Manguinhos 2007;14(3):801-821.

9. Wandekoken KD, Dalbello-Araújo M. Trabalho nos Centros de Atenção Psicossocial Álcool e Drogas e as Políticas Públicas: Que caminho seguir? Trab educ saúde 2015; 13(1):157-175.

10. Rodrigues DRSR, Conceição MIG, Iunes ALS. Representações Sociais do Crack na Mídia. Psic. Teor e Pesq 2015; 31(1):115-123.

11. Lima FAF. Justiça Terapêutica: em busca de um novo paradigma [tese]. São Paulo: USP; 2009.

12. Santos ALG, Farias FR. Criação e extinção do primeiro Manicômio Judiciário do Brasil. Rev Latinoam Psicopatol Fundam 2014; 17(3):515-527.

13. Reis JRF. "De pequenino é que se torce o pepino": a infância nos programas eugênicos da Liga Brasileira de Higiene Mental. Hist cienc saude-Manguinhos 2000; 7(1):135-157.

14. Amarante P, organizador. Archivos de Saúde Mental e Atenção Psicossocial. Rio de Janeiro: Nau Ed; 2003.

15. Machado LV, Boarini ML. Políticas sobre drogas no Brasil: a estratégia de redução de danos. Psicol Cienc Prof 2013; 33(3):580-595.
16. Silva CCR. A aliança entre justiça e psiquiatria no controle do uso de droga: medicalização e criminalização na berlinda. Rev Epos 2013; 4(1):1-24.

17. Castel R. A Ordem Psiquiátrica: a idade de ouro do alienismo. Rio de Janeiro: Ed. Graal; 1978.

18. Vargas EV. Entre a extensão e a intensidade: corporalidade, subjetivação e o uso de "drogas" [tese]. Belo Horizonte: UFMG; 2001.

19. Musumeci B. O consumo de álcool no país. In: Zaluar, Alba. Organizadora. Drogas e cidadania: repressão ou redução de riscos. São Paulo: Brasiliense; 1994. p. 83-96.

20. Carneiro H. Pequena Enciclopédia da História das Drogas e Bebidas. Rio de Janeiro: Elsevier; 2005.

21. Silva MB, Delduque MC. Patologização e penalização do uso de drogas: uma análise socioantropológica de proposições legislativas (2007-2010). Physis 2015; 25(1):231-250.

22. Garcia MLT, Leal FX, Abreu CC. A política antidrogas brasileira: velhos dilemas. Psicol Soc 2008; 20(2):267276.

23. Batista N. Política criminal com derramamento de sangue. Rev Bras Cienc Criminais 1997; 5(5):129-146.

24. Delmanto J. Camaradas Caretas: Drogas e esquerda no Brasil após 1961 [dissertação]. São Paulo: Universidade de São Paulo; 2013.

25. Rodrigues T. Política e drogas nas Américas. São Paulo: Educ/FAPESP; 2004.

26. Carvalho JC. A América Latina e a criminalização das drogas entre 1960-1970: prenúncios de outra guerra por outra América. Rev Unifeso 2015; 2(2):78-98.

27. Del Olmo R. A face oculta da droga. Rio de Janeiro: Revan; 1990 .

28. Luchmann LHH, Rodrigues J. O movimento antimanicomial no Brasil. Cienc Saude Colet 2007; 12(2):399407.

29. Estrela KSR, Loyola CMD. Administração de medicação de uso quando necessário e o cuidado de enfermagem psiquiátrica. Rev bras Enferm 2014; 67(4):563-567.

Artigo apresentado em 16/12/2016

Aprovado em 10/05/2017

Versão final apresentada em 12/05/2017 